\title{
Afterword: Interrogating naturalisation, naturalised uncertainty and anxious states
}

\section{Anne-Marie Fortier}

\section{Lancaster University}

\section{Abstract}

This afterword addresses four broad questions raised by this special issue: uncertainty as a mode of governance, the ontological politics of naturalisation, the citizen-noncitizen distinction, and performative (anxious) states. First, taking uncertainty as a mode of neoliberal governance as the starting point of analysis, this afterword invites the scrutiny of the ways in which the artifice and uncertainty of citizenship are concealed or rendered irrelevant in naturalisation processes. Second, the contributions to this special issue consider naturalisation as a social and political process, rather than solely as a legal status. Pushing this conception further, this afterword considers naturalisation as transactional in two ways: on the one hand, migrants navigate a number of formal and informal requirements and 'tests', where some transactions are needed along the way, be they financial, practical, or symbolic. On the other hand, transactions will also occur in the translation of political ideology into policy. Third, naturalisation regimes both blur and reify the citizen-noncitizen and the citizen-migrant distinctions. Distinctions which this afterword unpacks by unravelling the assumed separation between citizenship and migration. How are citizens and migrants migratised? How are migrants and citizens citizenised? Fourth, a further element of the analysis concerns how state-citizen relations are enacted and by extension, how the state itself is 'made up' and 'anxious'. The affective politics of 'anxious states' are telling of the frames of desire of naturalisation, which are founded on a threefold principle: the desirability of citizenship, the desire for desirable citizens, and the desirability of the state itself. 
Keywords: naturalisation, citizenship, citizenisation, noncitizenship, migratisation, anxious state 


\section{Afterword: Interrogating naturalisation, naturalised uncertainty and anxious states}

It is December 2020 as I write these lines, the end of a year when the inequalities of citizenship were starkly brought to light by the Covid-19 pandemic, which magnified long standing global and national inequalities in the distribution of 'full' citizenship and the concurrent growth of precarious statuses that render the racially minoritised poor including indigenous populations - more disposable. What is more, international Black Lives Matter [BLM] protests that erupted in the summer of 2020 in the wake of the murder of African American George Floyd at the hands of a white police officer in the US, forced a reckoning with militarised policing and reactivated questions about the politics of memorialisation that celebrate colonial administrators and profiteers of slavery and racial capitalism. The inequalities and uncertainties of citizenship and how they function in the contemporary world were made raw by the combination of the pandemic with the BLM protests, which have been used in further attempts to control the movement of people within localities and not only across borders.

The inequalities of citizenship have long since been an object of discussion within academic scholarship as well as in the political and public domains. This special issue contributes to such debates with its focus on naturalisation and citizenship regimes in different context thanks to its focus on lived experiences of integration and naturalisation processes. While research on citizenship has grown exponentially since the 1980 s (Shachar et al. 2017: 4), how citizenship regimes, and naturalisation specifically, affect the lives of migrants in their country of residence remains under researched. This special issue makes a welcome contribution towards filling this gap. 
This issue is also a welcome intervention in conversations beyond citizenship studies and migration studies - and the sub-field of citizenship \& migration studies - extending debates about naturalisation into those of 'ethnicities', nationalism and related issues such as minority rights. Together, the articles gathered here shed much needed comparative light on the effects of naturalisation, integration and citizenship policies on those they target, but also on the changing boundaries of the nation and citizenship. Citizenship's instrumentalised malleability as it operates as a bordering technique is the object of this issue.

Another feature of this collection is that it uncovers the co-existence of and indeed tensions between multiple models of citizenship within national settings, unravelling normative ideals of liberal democracies based on a single model of citizenship (the terms of which are open to debate; van Oers in this issue). But more than that, the articles in this issue open questions about whether citizenship can ever be fully achieved, highlighting its conditionality but also implying its precarity and indeed fickleness to political debates and policy makers' susceptibility to them (as intimated in Suvarierol's contribution).

In that regard, the issue opens with a remark by the guest editors about the 'troubling observation' that citizenship has become increasingly difficult to obtain and that there is an enduring gap between citizenship as legal status and citizenship as social status (Bassel et al. in this issue). Why are we still troubled by the gap between the promise of citizenship and the 'reality' of it? For despite its increasingly noted fragility and the widely recognised chasm between citizenship ideals and citizenship practices, the idea of citizenship as a stabilising status endures. Taking this as my starting point, I reflect back on the articles in this issue and consider four sets of questions that they generate: uncertainty as a mode of governance, the ontological politics of naturalisation, the citizen-noncitizen distinction, and performative (anxious) states. 


\section{Uncertainty as a mode of governance}

Citizenship is uncertain. It is volatile, its boundaries, limits and promises are forever revised, amended, and deferred. The certainty of the uncertainty of citizenship is undoubtedly a feature of this special issue. But uncertain citizenship is not new. Rather, a long view of the colonial and anticolonial histories of citizenship reveals how uncertainty was embedded within citizenship from the onset.

Writing about his own status as a colonial subject back in 1998, Jacques Derrida argued that 'citizenship is, through and through, precarious, recent, threatened, and more artificial than ever.' (1998: 15) Drawing on his Franco-Maghrebian status, he went on to explain how he both lost and regained his citizenship in the course of his lifetime. For Derrida, the uncertainty of citizenship is not only about the deprivation of citizenship of targeted individuals; it is about how this can also happen to

a "community" group [..], a supposedly "ethnic" or "religious" group that finds itself one day deprived, as a group, of its citizenship by a state that, with the brutality of a unilateral decision, withdraws it without asking for their opinion, and without the said group gaining back any other citizenship. No other. (1998: 15)

This bears disturbing resonance with the Windrush scandal, which came to light in the Spring of 2018. While the outcome was no doubt different, with many of those affected seeing their citizenship status regularised, the effects but also the basis of this 'scandal' were the same.

The scandal affected those known as 'the Windrush generation', migrants arriving on British soil between 1948 and 1973 from former colonies as 'Citizens of the United Kingdom 
and Colonies' (CUKC) - with rights to remain, to work, to settle in the UK - who were at risk of being deemed 'illegal' residents for lack of adequate documentation'1: as a result, 164 individuals, all of whom from the Caribbean, have been detained or deported since 2002 (Williams 2020). ${ }^{2}$ But the scandal affected hundreds of others, directly or indirectly, with some losing their jobs, access to national health services, and having their lives turned upside down.

I elaborate elsewhere on the ramifications of this scandal and its implications for understanding the inherent character of citizenship beyond Britain (Fortier 2021). The point I wish to make here is that those racially minoritised (post)colonial citizens were subjected to firmly institutionalised structures of racial governmentality that enabled their citizenship to be questioned by Home Office officials seeking to reach their deportation targets (ElEnany 2020; Goodfellow 2019; Williams 2020). What we learn from the Windrush scandal is not only that citizenship is uncertain: that it changes, is unstable, and subject to the conjuncture of political, economic, and social events and interests. The Windrush scandal also reveals how uncertainty disproportionately affects racially minoritised people, and that the racialised uncertainty of citizenship is historically embedded, rather than contingent on national institutional and political 'cultures' (path-dependency) or international trends (cross-national convergence). This is about recognising the historical legacies of structures, discourses and imaginaries - such as the racial state (Goldberg 2002) and 'racial thinking' and to ask how they manifest themselves in specific contexts and at specific times. What counts as citizenship is continuously re-shaped and re-defined, while at the same time, there remain some constants such as the colonial impetus of European imperialism that enduringly questions the rightful presence of racially minoritised citizens and residents in European countries (Tudor 2018; El-Enany 2020). Unpacking 'uncertain citizenship', then, 
must recognise that there are international trends or 'converging outcomes' that need to be understood in context in order to better capture the specific histories and social political climates that shape and impact on definitions of, and inequalities within, citizenship regimes.

An additional conclusion that I draw from this issue is the large-scale normalisation of uncertainty. That is, what was once lived, understood, experienced by colonial and racially minoritised subjects is now established and widely understood as the normal state of things, albeit with enduring disproportionate consequences for the racially minoritised (Bhattacharyya 2015). The question of how to make sense of citizenship policy changes in the past twenty years, which the guest editors ask, requires a conjunctural analysis that tracks the circumstances that enable current understandings of conditional and uncertain citizenship policies to become common sense. In contemporary forms of neoliberal governance, precarisation and uncertainty constitute instruments of governing rather than being threats to the social order that past welfare states would protect its citizens from (Lorey 2015). In a world where uncertainty is normalised, then, certainties like 'citizenship' are also normalised as uncertain. I scrutinise elsewhere (Fortier 2021) two interrelated aspects of contemporary neoliberal governance that shaped the rise of citizenship policies as they broadly exist today: firstly, dispersed governance, the citizenship industry and 'skillified' citizenship (Millar 2014), and secondly the connection between household governance, domestication and securitisation.

With this in mind, the question is not only what the current policies and their differential effects on subjects are. The question is also how the promise of the certainty of citizenship endures even as it is normalised as uncertain: how does uncertainty play itself out? What forms does it take? How is it smoothed over (or not) in practices of assessing, 
granting, learning about and applying for citizenship? And what are the dynamics and experiences that arise in a process where achieving citizenship makes all the uncertainties and anxieties to obtain it appear as worthwhile?

Taking uncertainty as a mode of neoliberal governance as the starting point of analysis invites the scrutiny of the ways in which the artifice and uncertainty of citizenship are concealed or rendered irrelevant in what I call 'citizenisation'. ${ }^{3}$ This ties in with a social ontological analysis of 'naturalisation', which I turn to now.

\section{Interrogating naturalisation}

What do we assume about 'naturalisation' as a theoretical and practical concept as it functions in citizenship theory and in the practice of citizenship attribution today? And how do social analyses of 'citizenisation' $-21^{\text {st }}$ century integration and naturalisation measures aimed at a range of presumed 'noncitizen' populations - lead us to redefine naturalisation and its relationship to integration and citizenship?

Legally speaking, naturalisation refers to the acquisition of citizenship and nationality by somebody who resides in a country where she or he is not a citizen or national. In contrast to the accepted understanding of legal naturalisation as a voluntary act, 'naturalisation' 'denotes the opposite of choice', as Christian Joppke points out (2010: 16). For through 'naturalisation', something is 'made natural' - brought into conformity with nature - as in the case of aligning one's permanent place of residence with one's nationality. In this form, 'naturalisation' re-establishes the 'natural' order of things because citizenship takes as its baseline assumption that most of us reside in the country into which we are born. Furthermore, stating that something is 'natural' establishes a value judgement about what is socially acceptable and desirable. As Judith Williamson explains in her theory of 
decoding ideology and meaning in advertisement, ideas of what is 'natural' result from a transactional relationship between 'nature' and 'culture'. She writes:

precisely because of this reference to Nature as the determinant of what is good, as though it were an independent arbiter, "the natural" becomes the meaning given to culture, by nature - although it is culture that determines "the natural" anyway. (1978: 123) An understanding of 'naturalisation' as a social and cultural process and product resulting from transactions between culture and nature rather than solely as a legal process, allows us to examine how it continues to 'make sense' within the realm of citizenship attribution. This takes us to a deceptively simple question: what is naturalised in naturalisation? This is more than a matter of semiotics. It is about how, in practice, integration and naturalisation are variously enacted, the different realities they bring forth, and the 'ontological politics' (Mol 2002) surrounding the choice of some realities over others (Law 2004: 13).

Naturalisation, then, is transactional in two ways. First, as highlighted in the articles in this issue, where migrants navigate a number of formal and informal requirements and 'tests', which means that some transactions are needed along the way, be they financial (test and application fees), practical (finding a babysitter, getting a half-day off, cancelling a holiday), or symbolic (displaying belonging, believability, or desire for the state). Transactions will also occur in the translation of policy into practice; taking the UK as an example, the changes in the Life in the UK test adopted in 2013 was a direct effect of a change in government and ideology; it resulted from a political transaction between a more conservative ideology and its translation into a new citizenship test that, as the then Minister for Immigration Mark Harper said: 
stripped out mundane information about water meters, how to find train timetables, and using the internet. The new [citizenship test] rightly focuses on values and principles at the heart of being British. Instead of telling people how to claim benefits it encourages participation in British life (BBC News 2013)

The second type of transactional relation within 'naturalisation' relates to social ontological processes through which 'realities' and subjectivities are naturalised. This is more than assessing policies against citizenship models or within transnational convergence or national path dependence models, on the one hand, or dismantling citizenship as 'acts' or as a technology of governance on the other - however pertinent these are. What is also needed is to bridge understandings of naturalisation as legal and political processes with understandings of naturalisation as a social process. Theoretically, extending a social understanding of naturalisation into formal 'integration' measures is to scrutinise how integration and citizenship are framed, enacted and experienced, and to unpack the multiple 'realities' assumed under 'citizenship'. To be sure, the 'unnatural' character of citizenship is widely accepted in current scholarship on citizenship and migration. At the same time, the unquestioned distinction between chosen and ascribed citizenship still dominates the policy and theoretical worlds of 'integration and naturalisation', which suggests the endurance of some baseline assumptions about the 'reality' of how and why one acquires citizenship. Put differently, we need to understand naturalisation as part of wider processes that shore up understandings of the inevitability of citizenship as the 'gold standard'. Thinking about the social life of citizenisation - which combines both 'integration and naturalisation' measures as legal and social processes - requires an analysis of how different categories or locales of existence (citizen/ship, the state, the nation, [imperial] 
histories, geographies) are called forth and 'naturalised' in citizenisation practices, and how they combine to produce understandings of what citizenship 'really is'.

For example, we live in a world where principles of birthright entitlement and kinship dominate not only our imagination but also our laws in the allotment of political membership. These laws renaturalise "the "wealth-preserving" aspect of hereditary citizenship' (Shachar and Hirschl 2007: 274; Shachar 2009) and preserve the unequal global distribution of the world's riches. While where we are born may be 'accidental', the unequal distribution of our ensuing life-chances is not. As a result, assumptions about the free, autonomous, choosing migrant (mentioned in Winter in this issue) comes with the further assumption that this subject is free to pursue happiness and 'the good life' (Fortier 2021). But this pursuit is entrenched in global inequalities of the 'accidents of birth' that direct individuals, as Sara Ahmed (2010) argues, to what is naturalised as being the cause of happiness: citizenships of the Global North. Migrants pursuing the good life (or a better life) force the interrogation of how ideas of 'the good life' and happiness circulate globally, and which social, cultural, and national values are privileged in the process - such as the British value/valuing of 'active citizenship' scrutinised by Bassel, Montforte and Khan in this issue.

\section{Citizens and noncitizens}

Citizenisation regimes both blur and reify the citizen-noncitizen and the citizen-migrant distinctions. Citizenisation is a performative border-marking process that distinguishes citizens from noncitizens/migrants, but where noncitizenship is largely 'no more than a hypothetical category that enables the terms of citizenship to be articulated.'

(Bhattacharyya 2015: 29; my emphasis). There are several ways in which this binary is blurred or reified. 
First, uncertainty as a mode of neoliberal governance constitutes a social intervention that reaches into 'the fabric and depth' of society as a whole (Foucault 2008: 145) and embeds the conditionality of citizenship into popular consciousness (Honig 2001; Bhattacharyya 2015). One of the ways uncertainty plays itself out reproduces the racialised distinction between 'citizens' and 'noncitizens' (or naturalised citizens), where 'citizens' may rest assured that their citizenship is stable as they witness the citizenship of foreigners or naturalised citizens as more precarious - witness the Windrush scandal. Another example is the formalisation and instrumentalization of language in citizenisation processes in ways that ties it to citizenship, nationality and belonging. Kamran Khan's article in this issue also shows how hidden forms of assessment beyond the testing room is a form of uncertainty that extends the threat for potential discrimination and exclusion from gaining citizenship. In turn, I would argue that language requirements stabilise and secure the citizenship of the (white) monolingual 'national language' speaker and 'migratises' or 'racialises' those who speak otherwise (Fortier 2021).

Second, the citizen-noncitizen/migrant division maps onto the separation between political versus non-political subjectivity. Citizenisation policies operate from the broad assumption that noncitizens/migrants are not only non-members of the state in which they reside, but that they are also non-political subjects, even though, to use a simple example, some migrants might have some voting rights in their countries of residence such as Commonwealth citizens in the UK or EU citizens residing in other EU countries. The point here is that underpinning citizenisation processes is the idea that there is an outside, 'a space of non-citizenship where [citizenship] rights and entitlements do not apply.' (Bhattacharyya 2015: 28; Bhambra 2015). 
Third, if citizenising subjects is integral to citizenisation, so too is their decitizenisation. That is, by reifying the citizen-noncitizen/migrant boundary, citizenisation strips migrants of their other citizenships - symbolically if not legally - by making them irrelevant and in some instances undesirable to 'naturalised' citizenship. Moreover, the citizen-noncitizen/migrant opposition is intertwined with another distinction: the migratisation-demigratisation of those who become naturalised citizens. The narrative arc of the citizenisation process is to conclude with the inclusion of 'new' citizens as insiders who belong - therefore demigratising them by substituting their migrant status with their citizenship status. However, the Windrush scandal reminds us that one can be a citizen and still be seen as a migrant and reveals the ways in which racist ideologies of national belonging and entitlement framed the way that hostile anti-immigration policies are enacted. It is telling that the Windrush compensation scheme is framed as being 'for people who arrived in the UK many years ago and do not have documentation confirming their immigration status.' (Home Office 2020: 3; my emphasis). By stating that the aim is to redress their immigration status rather than their citizenship status, this language is telling of how racially minoritised subjects are perpetually migratised as noncitizens, which in turn racialises the British national citizenship as white.

Fourth and turning to the blurring of citizens and noncitizens, we can also ask how and to what extent citizens and citizenship themselves are migratised (Anderson 2013, 2019) - how citizenship itself is an immigration status (Yeo 2018) or how migration regimes intrude into the lives of non-naturalised citizens. For example, immigration regulations encroach in the lives of citizens such as bureaucrats who are variously tasked with implementing citizenisation policies or individuals in a relationship with a foreign spouse. Moreover, citizenisation regimes converge with immigration regimes as they are available to 
those that the state has already identified as potential future citizens (as opposed to those that the state has already deemed 'unfit' for citizenship, such as unskilled migrants on shortterm visas). 'Integration' is a function of 'the pre-emptive establishment of differential entitlement' that distinguishes between those deemed integratable and 'those deemed lesser at the outset' (Bhattacharyya 2015: 132). In other words, skills and criteria for establishing one's human capital become pre-emptive measurements of their integration potential, as well as, where applicable, their longer-term citizenship potential.

Finally, migratisation can take the form of migratism, which 'ascribes migration to certain bodies and establishes non-migration as the norm of intelligible national and European belonging.' (Tudor 2018: 1058) Racially minoritised subjects are presumed outsiders even when citizens; or, as I show elsewhere (Fortier 2021), racially majoritised but linguistically minoritised subjects such as white-bodied Europeans residing in Britain are expelled from the nation. Through intertwined regimes of seeing and regimes of hearing, migratism and racism together enable the concealment of 'whiteness' and 'national' as unmarked historically constructed categories that developed through histories of domination. Such erasures are normalised in bureaucratic processes and evidence-based methodologies of documentation that underpin common-sense politics of 'national values', 'national language' and 'the good life'.

\section{Performative (anxious) states}

Though aimed at presumed 'noncitizens', citizenisation policies are very telling of the ways in which the state represents and imagines 'good citizenship' and its relationship to citizens. A concurrent element of the analysis, then, concerns how state-citizen relations are enacted and by extension, how the state itself is made or remade. This means examining how 
citizenship, the state, and the state-citizen relationship come to be through enactments of policy (Shore et al. 2011; Newman 2013; Clarke et al. 2015; Hunter 2015). In the vein of literature on the 'performative state' (Weber 1998; Sharma and Gupta 2006), literature on policy enactment sheds light on how the state is not a pregiven, disembodied and unified decision-maker. Rather, these theories insist on rethinking how the state is 'made up', in Davina Cooper's words (2015), in both senses of how it is imagined and how it is actualised in everyday practice.

This analytical lens extends into 'anxious states'. That is, the affective politics and psychic power of state policies not only affect individuals, but they are also telling of the frames of desire of the policies themselves, which are founded on a threefold principle: the desirability of citizenship, the desire for desirable citizens such as those who embrace the national identity (Bartram in this issue), and the desirability of the state itself whereby applicants for citizenship and migrants more broadly are consistently cast as seeking the state's approval for admission into the polity (Fortier 2013, 2017).

If we are to further examine 'anxious states', we could complement research from below and research from above with research from 'within', where migrants and state actors meet. Indeed, the scrutiny citizenisation as it is enacted and experienced by both applicants and other actors drafted by the state to assess or deliver services to applicants is largely overlooked in the scholarship on citizenship and migration. Examining the ways in which various state actors or policy practitioners interpret, implement and interact with migrants, challenges assumptions that the latter operate in a uniformly predictable manner (Suvarierol in this issue). De Wilde and Duyvendak's (2016), for example, examine of how local government representatives (as well as local residents) experience a policy aimed at community-building that the government representatives are tasked to implement in a 
neighbourhood on the periphery of Amsterdam. This type of research advances understandings of the local effects and affects of practices of governing. But more than that: it allows for a recognition that policy practitioners are more 'fully human' than they are often made out to be when they are conceived of simply as 'agents of the state' (Hunter 2015). They are also affected by what they do, who they meet, how they are positioned, and their own relationship to the state. Furthering our understanding of 'anxious states' requires moving beyond a view that posits those acting on behalf of the state as uniformly part of different 'cultures' than those who are the subjects affected and targeted by state policies. Rather, the object is to draw out how all these actors may be 'implicated in a set of shared and divergent forces that bring [them] together and move [them] apart.' (Povinelli 2011: 84). For example, some processes require that state actors and applicants meet in language or citizenship classes, interviews, applications checks, or in citizenship ceremonies. In such encounters, applicants are indubitably cast as 'migrants', and state intermediaries indubitably as 'citizens' endowed with the authority to teach about, advise on, assess one's eligibility for, or bestow citizenship. But state actors can also have an ambivalent relationship to the state as they too navigate the notoriously volatile legal landscape that is citizenisation, or their engagements with applicants or new citizens can be at times caring, such as the state actors who care enough to advise on the best way to put an application together beyond their functionary duties, or who care so much that they lose sleep (Fortier 2021).

\section{In conclusion}

The articles in this issue go a long way in unpacking citizenship regimes as border-making processes that reveal the inherent uncertainty of citizenship, which is a feature of 
contemporary 'anxious societies'. Uncertainty as a mode of governing citizenship is not new. But its contemporary manifestation in neoliberal governance must be scrutinised for their differential impact on migrants and on citizens. Citizenisation is a social intervention that entrenches the conditionality of citizenship in popular consciousness, while also shoring up the citizen-noncitizen distinction. The articles in this issue force the question about what is naturalised in 'naturalisation', such as the citizen-noncitizen distinction which unravels when considered through the lens of migration. Studying citizenisation and migratisation and how they work together calls for the consideration of how some shared local, national and global trends not only congregate and take form in specific social, political and historical contexts. This special issue crucially reminds us of the importance of exploring the effects of citizenisation on those they target as well as those variously tasked with implementing these policies, while recognising the power differentials between and different consequences for migrants seeking naturalisation on the one hand, and state actors on the other. Scrutinising the social relational dynamics of citizenisation reveals how hierarchies and systems of stratification are (re)produced not only politically, discursively and materially, but also through affect within and across anxious states.

\section{References}

Ahmed, Sara (2010) The Promise of Happiness. Durham (NC): Duke University Press. Anderson, Bridget (2013) Us and Them? The Dangerous Politics of Immigration Control. Oxford: Oxford University Press. Anderson, Bridget (2019) 'New directions in migration studies: towards methodological denationalism', Comparative Migration Studies 7(36): 1-13. 
BBC News (2013) 'UK citizenship test "to cover Britain's greats"', BBC News, 28 January. Available at https://www.bbc.co.uk/news/uk-21221773 [last accessed 29 March 2019] Bhambra, Gurminder (2015) 'Citizens and others: the constitution of citizenship through exclusion', Alternatives: Global, Local, Political 40(2): 102-114. Bhattacharyya, Gargi (2015) Crisis, Austerity and Everyday life. Living in a Time of Diminishing Expectations. Basingstoke: Palgrave Macmillan.

Clarke, John, Dave Bainton, Noemi Lendvai, Paul Stubbs (2015) Making Policy Move: Towards a Politics of Translation and Assemblage. Bristol: Policy Press.

Cooper, Davina (2015) 'Bringing the state up conceptually: Forging a body politics through anti-gay Christian refusal', Feminist Theory 6(1): 87-107.

de Wilde, Mandy and Jan Willem Duyvendank (2016) 'Engineering community spirit: the pre-figurative politics of affective citizenship in Dutch local governance', Citizenship Studies 20(8): 973-993.

Derrida, Jacques (1998) Monolingualism of the Other. Stanford: Stanford University Press. El-Enany, Nadine (2020) (B)ordering Britain. Law, Race and Empire. Manchester: Manchester University Press.

Fortier, Anne-Marie (2013) 'What's the big deal? Naturalisation and the politics of desire', Citizenship Studies, 17 (6-7): 697-711

Fortier, Anne-Marie (2017) 'The psychic life of policy: desire, anxiety and "citizenisation" in Britain', Critical Social Policy 37(1): 3-21.

Fortier, Anne-Marie (2021) Uncertain citizenship. Life in the waiting room. Manchester: Manchester University Press. Foucault, Michel (2008) The Birth of Biopolitics: Lectures at the Collège de France, 19781979. Basingstoke: Palgrave Macmillan. 
Goldberg, David Theo (2002) The Racial State. Oxford: Blackwell.

Goodfellow, Maya (2019) Hostile Environment: How Immigrants Became Scapegoats. London: Verso.

Home Office (2020) Guide AN. Naturalisation Booklet - The Requirements. London: Home Office.

Honig, Bonnie (2001) Democracy and the foreigner. Princeton: Princeton University Press. Hunter, Shona (2015) Power, Politics and the Emotions: Impossible Governance? London and New York: Routledge.

Joppke, Christian (2010) Citizenship and Immigration. Cambridge: Polity.

Law, John (2004) After Method. London: Routledge.

Lorey, Isabell (2015) State of Insecurity: Government of the Precarious. London: Verso.

Millar, Jeffrey Darren (2014) The revaluation of the national language in a post-national era: Language policy and the governance of migration and citizenship. unpublished doctoral thesis, Doctor of Philosophy: Linguistics, York University.

Mol, Annemarie (2002) The Body Multiple: Ontology in Medical Practice. Durham (NC): Duke University Press.

Newman, Janet (2013) ‘Performing new worlds? Policy, politics and creative labour in hard times', Policy and Politics 41(4): 515-532.

Povinelli, Elizabeth (2011) Economies of Abandonment. Durham (NC): Duke University Press. Shachar, Ayelet (2009) The Birthright Lottery. Cambridge (MA) and London: Harvard University Press.

Shachar, Ayelet and Ran Hirschl (2007) 'Citizenship as inherited property', Political Theory 35(3): 253-287. 
Shachar, Ayelet, Rainer Bauböck, Irene Bloemraad, Maarten Vink (2017) 'Introduction: citizenship - Quo Vadis?'. In: A. Shachar, R. Bauböck, I. Bloemraad and M. Vink (Eds) The Oxford Hanbook of Citizenship. Oxford: Oxford University Press: 3-11.

Sharma, Aradhana and Akhil Gupta (Eds) (2006) The Anthropology of the State. Oxford: Blackwell.

Shore, Cris, Susan Wright and Davide Però (Eds) (2011) Policy Worlds. New York, Oxford: Berghan Books.

Tudor, Alyosxa (2018) 'Cross-fadings of racialisation and migratisation: The postcolonial turn in Western European gender and migration studies', Gender, Place and Culture 25(7): 10571072.

Weber, Cynthia (1998) 'Performative states', Millennium: Journal of International Studies 27(1): 77-95.

Williams, Wendy (2020) Windrush Lessons Learned Review. An Independent Review by Wendy Williams. London, Stationary Office.

Williamson, Judith (1978) Decoding Advertisements. London: Marion Boyars Publishers. Yeo, Colin (2018) 'Citizenship, loyalty and treason in British nationality law', paper presented at the workshop on Resurgences of national citizenship in Europe? Manchester University, 11 December.

\footnotetext{
${ }^{1}$ The British government did not automatically issue them documents to prove their rightful presence when they arrived. Nor did the Home Office keep records (Williams 2020: 24). 'Windrush' refers to the HMS Empire Windrush, a ship that docked at Tilbury Docks, Essex, on 21 June 1948, with 1,027 official passengers on board.
} 
Of these, 802 stated their last country of residence was in the Caribbean. The Windrush 'has come to symbolise post-war Caribbean migration to the UK at the end of the empire.' (Williams 2020: 24)

${ }^{2}$ Measures addressing 'illegal working' had been in place prior to the hostile environment policy created by Theresa May when she was Home Secretary in 2012, which played a significant part in the scandal. Some people from the Windrush generation had already been removed or refused re-entry by the time May's policy was implemented. (Williams 2020: 53)

${ }^{3}$ It is beyond the scope of this article to explain my theory of citizenisation as a way to explore and rethink the relationship between integration and naturalisation. Suffice to say that 'citizenisation' refers to contemporary policies and citizenship regimes discussed in this issue and encompasses both integration and naturalisation and how they work together institutionally and socially - rather than conceiving them as separate moments on a same continuum. A theory of citizenisation seizes the processual and social lives of citizenship as it is made, unmade, and (dis)connected to 'migrants' and migrantood, but also to non-migrant 'citizens' themselves. Put simply, citizenisation is about how both presumed citizens and noncitizens are variously 'citizenised' and 'migratised'. See Fortier 2021. 